\title{
Planning and the Environment
}

\author{
J. Peter Clinch \\ Department of Planning and Environmental Policy, University College Dublin
}

\begin{abstract}
This paper discusses the relationship between planning, sustainable development and the environment in Ireland. The paper firstly explores the development of planning as a concept. It then sets out the key 'actors' in Irish environmental policy. The paper goes on to describe the planning system in Ireland with a specific emphasis on its relationship to sustainable development and the environment. Irish environmental performance is assessed. Irish environmental policy 'drivers' are then examined with a view to explaining the emphasis of Irish environmental policy. The paper demonstrates and explains the lack of influence of the planning system on key areas of environmental policy but emphasises its importance in addressing, in particular, urban and suburban environmental problems. The paper identifies the following impediments to the effective operation of the planning system in enhancing sustainable development: lack of consistency in government policy and legislation as regards sustainable development; poor public perception of planning and the role of political system therein; limited policy instruments and the emphasis on regulation; and lack of research for evidencebased policymaking.
\end{abstract}

\section{Introduction}

If one asks Irish students entering a postgraduate planning course to provide a definition of planning, a consensus is unlikely to be reached on its meaning or purpose. Expressions which usually emerge during a discussion include 'sustainable development', 'conservation', 'development control', 'economic development', 'environmental protection'. If one asks the Irish public what they understand planning to be, they would likely refer to the development control aspects of planning using phrases such as 'getting planning' and/or to perceived corruption in the planning system. These students and the public are not alone in their difficulty in defining or understanding planning. Indeed, in one of his many books, Sir Peter Hall $(2002,1)$ states that 'planning is an extremely ambiguous and difficult word to define'.

Hall $(2002,3)$ goes on to state that planning, in a general sense, does not refer to the art of drawing up a physical plan. Rather, the emphasis is on tracing an orderly sequence of events which will achieve a predetermined goal. The output of spatial planning practice before and after the Second World War was very minute and detailed and 'tended to consist of very precise large scale maps showing the exact disposition of land uses and activities and proposed developments'. In the 1960s, however, such an approach was criticised as being too proscriptive as to the end result and that planning needed to concentrate on broad principles.

\footnotetext{
${ }^{1}$ Hall (2002) shows how this difference in approach is reflected in a comparison of the UK Town and Country Planning Acts of 1947 and 1968.
} 
A former limitation of what was seen to be 'Town and Country Planning' or 'Regional and Urban Planning' was its focus on land. While the regulation of the use of land is still a fundamental issue in modern planning and may still be a key component of what might be viewed as the 'planning system', modern planning has become much more broad in its concerns. Perhaps the driving force behind this broadening of that which concerns planning has been the rise in environmental concerns and the notion of sustainable development. These environmental concerns involve not only land but also the atmosphere (air) and water but, more generally, quality of life.

Following on from the rise in environmental concerns in the $1980 \mathrm{~s}$, the concept of sustainable development became firmly established as part of the environmental debate in the aftermath of the Bruntland report of 1987 (which provided the most frequently cited definition) and has been prominent on the political agenda since the Rio Earth Summit in 1992. 'Sustainability' as an expression has, rather unfortunately, become somewhat of a buzz word that is often used by politicians but rarely defined in any operational sense. Breheny (1992) notes some 'frustration' in the way sustainable development as a phrase has come to dominate the debate, and tends to be used rather loosely, but notes that it has been useful for researchers and policymakers. The notion of sustainable development has certainly been particularly useful in focusing the minds of planning researchers and policymakers and has provided a revised rationale for planning because it involves the interaction between the economy, society and environment. As Raemaekers (2000) points out, the reconciliation of the demands of these three interlinked areas is commonly conceived to be the principal goal of planning.

The question to be addressed in this paper is the extent to which the planning system in Ireland addresses pressing environmental concerns. To examine this question, the paper briefly examines the key 'actors' in Irish environmental policy. It goes on to describe briefly the Irish planning system with a particular view to exploring its emphasis on sustainable development. It continues by assessing Irish environmental performance in recent years. The paper then explores the 'drivers' of Irish environmental policy with a view to explaining the emphasis of environmental policy. The paper concludes by exploring the lack of influence of the planning system on key areas of environmental policy but emphasises its importance in addressing, in particular, urban and suburban environmental problems. Some impediments to the effective operation of the planning system in enhancing sustainable development are outlined.

\section{Environmental Policy 'Actors'}

Key actors shaping Irish environmental performance are the following:

The Department of Finance has lead responsibility for the preparation and execution of the National Development Plan, for fiscal policy, and for controlling expenditure. It leads an interdepartmental group that reviews the fiscal situation and the potential for the application of fiscal measures to advance environmental objectives. It produces periodic reports.

The Department of Environment, Heritage and Local Government has lead policy responsibility for housing, water and air, waste, and for the planning system (see below). It allocates funding to local authorities for housing, local roads, water supply and wastewater treatment, and waste disposal. The Department led the preparation of a National Sustainability Strategy in 1997 which was followed by a National Spatial 
Strategy in 2002. It leads a 'Green Network of Government Departments' that comprises a network of Assistant Secretaries in departments with significant environmental impact. They aim to integrate environmental considerations into economic development. Eco-auditing is regarded as a key element in the attainment of such integration.

The Department of Community, Rural and Gaeltacht Affairs has responsibility for the promotion and support of the sustainable and inclusive development of communities, both urban and rural, including Gaeltacht and island communities, in order to foster better regional balance.

The key sectoral departments, Agriculture and Food (including forestry), Enterprise, Trade and Employment (industry), Communications, Marine and Natural Resources (freshwater and marine fisheries, mining, energy), and Arts, Sport and Tourism, have units addressed to the environmental aspects of their activities.

There are a number of government agencies and bodies with responsibilities for aspects of environmental performance. The Environmental Protection Agency is an independent organisation with responsibilities for licensing of industry (Integrated Pollution Control [IPC] licensing), environmental monitoring and enforcement (including production of state of the environment reports), research, and overview and support of the local authorities in the implementation of their responsibilities. The Heritage Council has responsibility for promoting conservation of the heritage endowment; ENFO has the lead responsibility for promoting public awareness of environmental issues and performance; Sustainable Energy Ireland (SEI) has an information role in promoting energy conservation and enhancing research in the area.

Policy as regards housing, water supply, wastewater treatment, solid waste and land use are implemented by the local authorities, from whom permission must be sought for most industrial, residential and commercial development. Decisions by the local authorities are based on the provisions of the Development Plan for the area for which they have jurisdiction (see below), and any policy guidance by the Minister for the Environment, Heritage and Local Government. The decision can be appealed by the proposer or by any third party to a national appeals authority (An Bord Pleanála) whose decision is final.

There are a number of non-governmental environmental organisations, including An Taisce, the National Trust for Ireland. Under the planning regulations, this organisation receives planning applications likely to be of significant environmental importance.

\section{The Irish Planning System and Sustainable Development}

The objective of the Department of the Environment, Heritage and Local Government (DEHLG) with regard to planning is 'To provide a policy and legislative framework which facilitates and encourages development patterns consistent with the principles of proper planning and sustainable development, balanced regional development, conservation of the natural and built environment, quality in construction and urban and village regeneration' (DELG, 2003).

Planning is the overall responsibility of the Minister of that Department, and the principal objective of the physical planning system is defined by the Government as 
being to 'facilitate and encourage development within sustainable patterns of settlement whilst fostering protection of the natural and built environment and promoting the efficient use of land and infrastructure' (DELG, 2003, 26). The key strategies of the DEHLG are to lead and manage implementation of the National Spatial Strategy (see below), to maintain an up-to-date legislative and policy framework to facilitate an efficient, effective, balanced and quality planning system which promotes sustainable development and to develop and maintain in cooperation with other and relevant interests targeted and integrated urban/town/village renewal programmes aimed at the economic, social and sustainable regeneration of such areas (DELG, 2003).

In terms of national-level planning, the Government published the National Spatial Strategy (NSS) in November 2002. This provides a twenty-year planning framework for Ireland. It aims to achieve a better balance of social, economic and physical development across Ireland, supported by more effective planning. In order to drive development in the regions, the NSS requires that areas of sufficient scale and critical mass be built up through a network of gateways and hubs. The NSS also identifies the need to support the role of smaller towns, villages and rural areas at the local level. The intention is that the NSS will be implemented through the translation of its policies into regional and local planning by regional and local authorities and the consideration of its objectives in all government policies.

In April 2004, the Minister for the Environment, Heritage and Local Government launched new guidelines on the vexed issue of rural housing. These state that, subject to good planning practice, people with rural links are to be favoured for planning permission for rural housing, as will any applicant applying for permission in an area suffering from population decline. Applicants for housing in rural areas must meet normal planning requirements in relation to matters.

Irish planning regulations are consolidated in the Planning and Development Act 2000. The Act recognised the centrality of the principle of sustainable development. The Planning and Development (Regional Planning Guidelines) Direction (2003) and Regulations (SI No.175) (2003) direct each Regional Authority to formulate regional planning guidelines for its region and oblige them to take account of the NSS.

Local Authorities are, in the first instance, responsible for local physical planning. The core components of this are the Development Plan, which is the principal instrument for the regulation and control of development, and Development Control, which involves the granting or otherwise of permission that is required for all developments unless specifically exempted. Certain developments must be assessed for likely environmental effects via Environmental Impact Assessment before planning permission can be granted while Strategic Environmental Assessments (SEA) provides for strategic environmental consideration at an early stage in the decision-making process (DEHLG, 2004).

The Government's Sustainable Development Strategy provides for local authorities to complete Local Agenda 21 (now termed 'Local Action') Plans for their areas. Each local authority was expected to enter into dialogue with its citizens, local organisations and private enterprises and adopt 'a local Agenda 21'. Through consultation and consensus building, the objective was that local authorities would learn from citizens and from local, civic, community, business and industrial organisations and acquire the 
information needed for formulating the best strategies. Each county council and county borough has a designated Local Agenda 21 Officer, and these are networked at regional and national levels (DEHLG, 2004). ${ }^{2}$

The following questions now arise: how has Ireland performed in recent years in relation to the environment? What are the key 'drivers' of environmental policy and what role does the planning system play in addressing key issues? The paper now endeavours to address these questions.

\section{Irish Environmental Performance}

The conference at which this paper was presented was concerned with reflecting on the first forty years of planning. For the first thirty years, Irish environmental performance on average was relatively good despite some notable exceptions (in particular some high profile damage to our architectural and archaeological endowments and the perverse environmental effects of the Common Agricultural Policy). It is sometimes said that this was the result of relatively poor economic performance such that there was less pressure on Ireland's environmental endowment than was the case in neighbouring European countries. However, in the last ten years, the Irish economy has been the fastest growing economy in Europe. The growth of output was unprecedented in an Irish context and the growth in employment a record in an international context. Between 1990 and 2000, Gross Domestic Product doubled with the real growth rate at a high of $11 \%$ in 1999 (Clinch et al., 2002). While the growth rate fell back considerably in the first few years of the new millennium, growth continues to be in the order of four to five per cent. While this extraordinary economic success, in particular the fall in unemployment, has been most welcome, the pace of the growth has had the potential to have significant implications for the environment. The question arises as to whether development has taken place in a 'sustainable' manner.

Standard national accounting procedures fail to reflect the deterioration in environmental quality that can result from economic growth. Therefore, the accounts do not give a true picture of our well-being. 'Green' accounting endeavours to reflect the value of environmental services in figures of national product. Scott (1999) develops parallel environmental accounts for the Irish economy for 1994 and recent figures can be obtained from the Central Statistics Office. However, this approach does not attempt to provide a single number that could characterise overall performance.

Achieving sustainability, however defined, involves creating and maintaining wealth. Following the pioneering work of Pearce and Atkinson (1995) there have been continuing efforts to expand the concept of net savings and consequent changes in wealth by adjusting conventional measures to include changes in natural resource stocks, changes in health and education, and changes in utility/well-being as a result of environmental degradation (Hamilton and Clemens, 1999; Hamilton, 2000). A key underlying assumption of the 'weak sustainability' rule is that forms of capital are substitutes. Man-made capital consists of those things made by humans such as

\footnotetext{
${ }^{2}$ Ellis et al. (2004) found that while the national policy framework in Ireland is well developed, the framework has not been fully successful in embedding sustainability values in local institutions and practices and while inclusive local partnership bodies such as city and county development boards are well placed to deliver sustainable development, so far they have been involved in planning and goal-setting but successful implementation is far less obvious.
} 
buildings, roads, machinery. Human capital represents the ability of humans to be productive and is potentially enhanced by investments in education and health. Natural capital consists of ecological services. This weak sustainability rule implies that a country could run down its natural capital but, if it were investing in education and health, it could be judged to be 'sustainable' according to this weak criterion (Clinch, 2002).

Genuine savings (GS), a form of green accounting, may be defined as Gross Domestic Product less consumption, depreciation, and depletion of natural assets, plus investment in education, primary health and research and development. There are difficulties in quantifying some of these adjustments. For example, damage estimates associated with air emissions are used as a proxy for most environmental degradation. A significant weakness with this approach is that it does not (although no alternative does better at this point) net out 'imported sustainability', e.g. if the manufacturing of the goods imported by Singapore results in the country of origin being unsustainable, this is not reflected in Singapore's rating. However, this work still represents considerable progress. The World Bank has published estimates for 100 countries which indicate that many developing countries fail the weak sustainability test, i.e. their net capital stock is in decline. Expressing these changes in per-capita terms for 1997, we find that Ireland's rapid growth gives it a high positive net savings rate leaving it ranked third in the world, behind Japan and Singapore (Table 1).

Table 1. Genuine-Savings Estimates for Selected Countries, 1997.

\begin{tabular}{lc}
\hline \multicolumn{1}{c}{ Top Six Countries } & $\begin{array}{c}\text { Genuine Savings per capita } \\
\text { (US\$) }\end{array}$ \\
\hline 1. Singapore & 8942 \\
2. Japan & 7087 \\
3. Ireland & 5027 \\
4. Belgium & 4419 \\
5. Sweden & 4051 \\
6. Germany & 4025 \\
\hline \multicolumn{1}{c}{ Bottom Six Countries } \\
\hline 1. Israel \\
2. Saudi Arabia & -4476 \\
3. Australia & -3770 \\
4. Venezuela & -1115 \\
5. Guatemala & -718 \\
6. Argentina & -572 \\
\hline
\end{tabular}

Source: Hamilton, 2000.

The countries that have high rates of genuine savings have some combination of high rates of savings and net investment, and low rates of domestic resource exploitation and environmental degradation. The large negative-savings countries have some combination of large net depletion of natural resources and environmental degradation, and low net savings and investment. Ireland comprehensively passes the 'weak sustainability' test. An important explanation of this is that the estimates of environmental degradation used in the calculation of net savings above exclude the most serious negative effects on quality of life in Ireland. Emissions to air are used as a proxy for environmental performance. Using this measure, Ireland is seen to have a mixed performance over the 1990 s with better performance recently. 
Between 1990 and 1998, emissions of $\mathrm{SO}_{2}$ stayed relatively constant, but in 2002 was nearly half what it was at the beginning of the $1990 \mathrm{~s}$. CO was reduced by $25 \%$ between 1990 and 2002. However, emissions of greenhouse gases increased by $29 \%, \mathrm{NO}_{\mathrm{x}}$ emissions increased by $6 \%$, and Volatile Organic Compounds (VOCs) increased by $6 \%$ between 1990 and 1998 but are now about one-quarter less than in 1990. This compares with GNP growth over the same period of $100 \%$, so that while deterioration in an absolute sense is evident in some quarters, the rate of deterioration is much lower than the rate of GNP growth (Figure 1).

Figure 1. GDP, House Prices and Environmental Performance, 1990-2002.

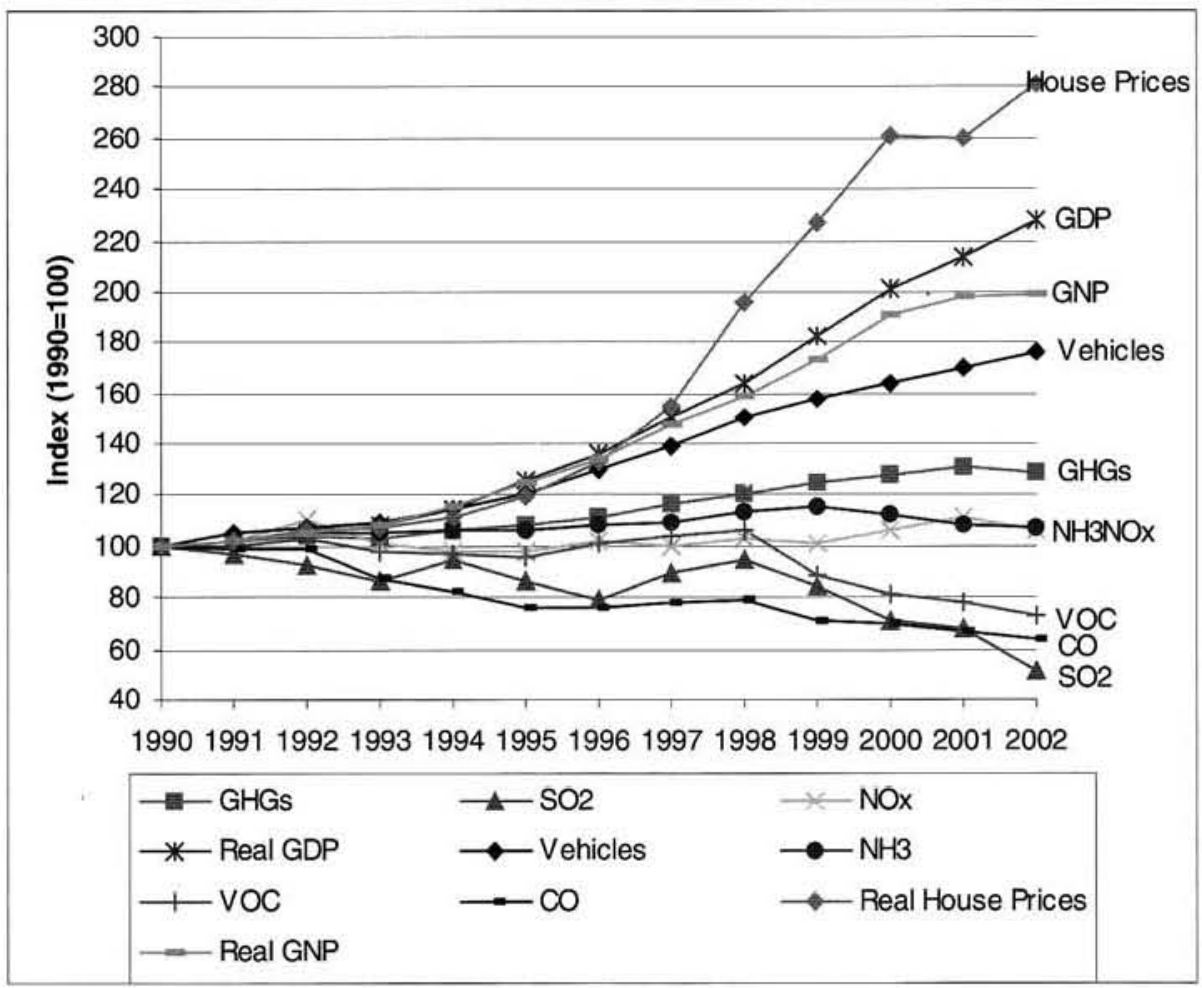

These figures should not be seen as reassuring when considering the policy constraints faced by Ireland under the Kyoto and Gothenburg protocols. For example, it is predicted that Ireland will exceed its greenhouse gas emissions target (of 13\% over 1990 levels) set in the Kyoto Protocol by a large margin. This is because most of this growth in greenhouse gas emissions has occurred since the 1990 base year. EPA (2004) estimates that Ireland is already $29 \%$ over its Kyoto limit. Ireland's unprecedented growth has resulted in estimates that, under a 'business as usual' scenario, total emissions would increase by between $37 \%$ and $41 \%$ by 2010 .

Even if, overall, these air emissions suggest reasonable performance, using them as a proxy for all environmental performance would be to ignore some environmental impacts that are of considerable import for quality of life and, especially perhaps, urban living. While incomes have risen, urban dwellers face increased road congestion, longer commuting distances, housing shortages, increased noise and generally less favourable 
environmental conditions. Using vehicle numbers as a proxy for congestion, it can be seen from Figure 1 that, unlike emissions to air, this environmental impact has been more in line with GNP growth. While between 1990 and 2002 GNP increased by $100 \%$, vehicle numbers increased by $76 \%$. Measurement of particulate matter emissions began in Dublin in 1996. Emissions have been reduced in the areas of most concern including College Green but the number of days exceeding limit values $\left(50 \mu \mathrm{g} / \mathrm{m}^{3}\right)$ is in excess of that which will be permitted by EU law in 2005 . The real rise in house prices has, of course, given 'pre-boom' owners a substantial capital gain, but for new entrants at the margin, the incremental costs are substantial. Noise complaints to Dublin Corporation almost doubled between 1996 and 1998.

In addition to the three-fold increase in real house prices between 1990 and 2003, the inadequacy of housing policy during the Irish boom has had a number of other negative effects. In particular, the spread of the Dublin commuter belt to include all of Leinster, and even further afield, has led to many undesirable externalities. These include further congestion, increased travel time to work, rising frustrations and stress, increased fuel use and associated greenhouse gas and pollution emissions. Much of the energy in the new Dublin economy is deriving from developments along the ' $\mathrm{C}$ ring' motorway circling the city to the west, with nodes at Swords/Dublin airport (Motorola, Hertz), Blanchardstown/Mullhudart (IBM complex), West Dublin/North Kildare (Intel, Hewlett Packard), Tallaght (City west, Park west) and Leopardstown/Sandyford (Microsoft, Cherrywood Technology Park). This development of an 'edge city' is symptomatic of developments in many urban areas, but has happened with particular rapidity in the Dublin region. Except for some apartment development in the inner city and some new large housing plans (e.g. Adamstown), most housing is low-density suburban, and this process of urban sprawl and dispersal seems to be accelerating, with much of the development leapfrogging the established commuter belt (Clinch et al., 2002).

\section{Environmental Policy Drivers and the Role of Planning}

In addressing the environmental challenges generated in the main by economic growth, Irish policymakers face a number of constraints. As regards domestic pressure for improved environmental performance, there is a direct negative feedback loop to the economy as regards environmental degradation. For the rapidly growing tourist industry, a high-quality environment, and heritage buildings and associated cultural endowments, are key assets. For the food industry, a high-quality environment is important for the image of the product in international markets. For the information technology and financial service industries, a high quality of life, including a good environment, is an important attraction for some high-, and relatively scarce, skilled workers and entrepreneurial talents.

Secondly, there is the pressure from Irish residents for a local high-quality environment. This is expressed most forcefully in the development of avoidance strategies concerning the location of landfill and incineration, but tends to be relatively weak as a source of pressure in relation to strategic national and regional issues such as congestion and settlement.

The question arises from Section IV as to why there is such a discrepancy in performance between air emissions and urban environmental indicators. Partly, it lies in what drives environmental policy in Ireland. It is generally not the indigenous concerns about quality just mentioned, but targets, in the form of assigned amounts or quotas in 
the case of greenhouse gases and acid precursors, in the form of emission standards in the case of wastewater treatment, or as ambient standards in the case of smoke and sulphur concentrations in the atmosphere. First, in a series of European Union Directives and Regulations, the Irish Government is obliged to meet legal obligations concerning a wide and growing range of issues, including: emission standards for waste water; ambient air and water standards; standards for drinking water; quantified targets for recycling and re-use of packaging; requirements for provision of environmental performance information; and identification and protection of a network of Special Areas of Conservation (SACs) comprising habitats for flora and fauna that are of Europe-wide significance. Provisions in the Amsterdam Treaty allow the European Court of Justice to impose large fines on Member States that are judged to be in noncompliance, so that the potential costs are real. Secondly, at global and European regional level, there are commitments not to exceed assigned amounts of greenhouse gases (Kyoto Protocol), to phase out the production and use of stratospheric ozone depleting CFCs (Montreal Protocol), and limits on emissions of acidification precursors (Gothenburg Protocol).

Generally, with the exception of a few key areas of concern such as environmental health impacts of, for example, siting of waste facilities (incineration particularly) and telephone masts, domestic concerns about environmental issues have been seen to be less immediate than legally binding European policies.

At present, the Planning system plays a limited role in addressing the principal international environmental policy issues for Ireland, in particular, meeting the Kyoto greenhouse gas limits and the Gothenburg Protocol targets and EU Directive on $\mathrm{SO}_{2}$, $\mathrm{NO}_{\mathrm{x}}$ and $\mathrm{PM}_{10}$, meeting water quality objectives in Irish and EU legislation, addressing the growth in energy demand in household and transport sectors (even though there is the potential for planning to have a greater role in this area) and dealing with ammonia reduction (acid precursor), eutrophication of water, nitrification of groundwater, biodiversity loss, and methane (greenhouse gas) from agriculture.

\section{Conclusions}

This paper has hypothesised that planning has had a limited role in addressing the issues of major concern to environmental policymakers. This is primarily because those concerns are driven by international policy drivers. Nevertheless, the planning system has a key role to play in addressing what have been demonstrated to be the most pressing environmental problems for Irish residents, in particular, urban and suburban environmental problems such as housing, transport infrastructure, and localised environmental performance such as noise reduction and improvements of urban amenities. Planning also has a key role in ensuring that rural environments which, at present, are of good quality, do not suffer due to poor planning practice.

Some of the failures of the planning system (including infrastructure delivery) are detailed elsewhere so it is unnecessary to repeat them here. However, key impediments to the effective operation of the planning system in regard to the environment include the following:

Lack of consistency in government policy and legislation as regards sustainable development: there are inconsistencies between the major policies which relate to spatial planning. For example, the Sustainable Development Strategy and the NSS 
encouraged sustainable development and commuting patterns whereas it is debatable whether the Sustainable Rural Planning guidelines will do likewise. Moreover, the Government's decentralisation policy is very inconsistent with the goals of the NSS. In addition, interpretation of legislation sometimes exposes the rhetoric of the integration of sustainable development and planning as expressed in the Planning and Development Act 2000. For example, the Chairman of the Appeals Board examining plans for the Ringaskiddy incinerator ruled that 'the appeals board was restricted under legislation to dealing with matters solely related to planning concerns and would be proceeding on this basis' and thereby ruled that submissions from anti-incinerator campaigners on the risk of environmental pollution for human health were out of order ('Ringaskiddy ruling angers objectors', 2003).

Poor public perception of planning and the role of political system therein: the planning system is the main interface between government and the public on environmental issues and is therefore of great importance. However, there is an over-emphasis on the development control aspects of planning. The many positive aspects of planning, such as development planning and provision of public goods, do not tend to be what is associated with planning in the public's mind. People naturally object when they perceive themselves as losing as a result of a development control decision whereas the many who win from a 'good' development control decision are less likely to notice and be supportive publicly. Planners, of course, do not always make the right decisions and in some instances have not been seen to be reactive to inquiries from the public (in some cases this may be due to inadequate resources). Nevertheless, it suits local politicians to be able to blame planners when a decision is made that does not favour a constituent even if the planner is merely implementing legislation laid down by the Oireachtas. Government, both local and national, needs to improve the public's understanding of the necessity for a planning system.

Limited policy instruments and the emphasis on regulation: planning has generally relied upon regulatory planning instruments, such as zoning and planning permissions, which have in some cases resulted in increased inequities. The introduction of development levies in the 2000 Act is welcome although their functioning has yet to be assessed. There is a need for an expansion in the use of market-based instruments (used successfully in environmental policy internationally) in order to provide more effective, efficient and equitable outcomes.

Lack of information for evidence-based policymaking: there is government funding for planning-related research. The information base on which planning decisions are made is appallingly poor. This allows vested interests to promote their opinions and they are just as valid as any other as there is little information to refute extreme claims. Thus, who shouts loudest or has most political power wins. This is particularly the case in the contentious issue of rural housing. There is a desperate need for a massive expansion in planning research at $\mathrm{PhD}$-level and beyond and the universities have an extremely important role in this regard but government (both local and national) must provide the funding. Such funding is miniscule in comparison to the costs associated with inappropriate planning decisions. 


\section{References}

Breheny, M.J. (1992) 'Sustainable Development and Urban Form: An Introduction', in Breheny, M.J. (ed) Sustainable Development and Urban Form, Pion, London.

Clinch, J.P. (2002) 'Reconciling Rapid Economic Growth and Environmental Sustainability in Ireland', the Barrington Prize Lecture, Journal of the Statistical and Social Inquiry Society of Ireland vol. 30, 159-218.

Clinch, J.P., Convery, F.J., and Walsh, B.M. (2002) After the Celtic Tiger: Challenges Ahead, O'Brien Press, Dublin.

DEHLG (2004) Department of the Environment, Heritage and Local Government website, <http://www.environ.ie> accessed 1 December 2004.

DELG (2003) Statement of Strategy 2003-2005, Department of the Environment and Local Government, Dublin.

Ellis, G, Motherway, B., Neill, W.J.V., and Hand, U. (2004) Towards a Green Isle? Local Sustainable Development on the Island of Ireland, Centre for Cross Border Studies, Armagh.

EPA (2004) Ireland's Environment 2004: The State of the Environment, Environmental Protection Agency, Dublin.

Hall, P. (2002) Urban and Regional Planning, Routledge, London and New York.

Hamilton, K. and Clemens, M. (1999) 'Genuine Savings Rates in Developing Countries', World Bank Economic Review vol. 13, no. 2, 333-56.

Pearce, D. and Atkinson, G. (1995) 'Measuring Sustainable Development', in Bromley, D.W. (ed) The Handbook of Environmental Economics, Blackwell, Oxford and Cambridge M.A.

Raemaekers, J. (2000) 'Planning for Sustainable Development', in Allmendinger, P., Prior, A. and Raemaekers, J. (eds) Introduction to Planning Practice, Wiley, Chichester.

'Ringaskiddy ruling angers objectors' (2003), Irish Times 24 September, downloaded from

$<$ http://www.ireland.com/newspaper/ireland/2003/0924/4172403456HM2ORALHEAR. html>

Scott, S. (1999) Pilot Environmental Accounts, Stationery Office, Dublin. 